\title{
The diversity of powdery mildew resistance gene loci among wheat germplasm in Southwest China
}

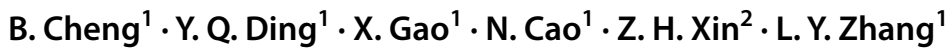

Received: 18 September 2019 / Accepted: 30 October 2019 / Published online: 11 February 2020

(c) The Author(s) 2020

\begin{abstract}
Knowledge of genetic diversity and genes conferring disease resistance is essential for the effective use of wheat germplasm resistant to powdery mildew in breeding programs in southwest China. In this study, a collection of 140 common wheat varieties was evaluated for their resistance to powdery mildew in four different environments. Thirty-six varieties (25.71\%) showed resistance in all four environments, and most of these varieties originated from the Guizhou Province. This collection was also scanned for molecular markers closely linked to the powdery mildew resistance genes. Most of the wheat varieties (79.86\%) carried the resistance Pm30 gene locus. Genotyping by sequencing (GBS) was used to screen our collection against the whole genome. Finally, 6864 informative SNP markers were used to construct a consensus tree with 1000 bootstraps, which showed two groups based on their origins and the presence of the Pm21 gene locus. Our results provide useful information for breeding wheat resistant to powdery mildew in China, and they will likely contribute to the identification of new resistance genes in the future.
\end{abstract}

Keywords Common wheat $\cdot$ Powdery mildew $\cdot$ Resistance genes $\cdot$ Genetics diversity $\cdot$ Genotyping by sequencing (GBS)

\section{Introduction}

Powdery mildew, caused by the obligate fungus Blumeria graminis f. sp. tritici $(B g t)$, is a destructive foliar wheat disease (Triticum aestivum L.). This disease can lead to severe yield losses in many wheat-growing regions of the world, especially in areas with humid and cool climates (Bennett 1984), such as southwest China. These climates provide a

Communicated by M. Taylor.

B. Cheng and Y. Q. Ding have contributed equally to this work.

Electronic supplementary material The online version of this article (https://doi.org/10.1007/s42976-020-00015-2) contains supplementary material, which is available to authorized users.

\section{Z. H. Xin}

1939572297@qq.com

$\triangle$ L. Y. Zhang

lyzhang1997@hotmail.com

1 Insititute of Upland Crops, Guizhou Academy of Agricultural Sciences, Guiyang 550006, Guizhou, China

2 College of Life Sciences, Guizhou University, Guiyang 550025, Guizhou, China source of inoculation and newly emerging virulences of the pathogen. Although fungicides controlling powdery mildew are available, development of resistant cultivars is the most efficient and environmentally friendly approach for controlling this disease (Hulbert et al. 2001). Resistance genes are abundant in plant genomes, and pyramiding these genes is a common breeding strategy to control powdery mildew. As a result, information on the distribution of powdery mildew $(P m)$ genes in resistant wheat germplasm will be a key factor for marker-assisted selection.

To date, more than $78 \mathrm{Pm}$ resistance genes have been formally identified in 50 loci in the genomes of wheat and its wild relatives (McIntosh et al. 2014; Xiao et al. 2013; Ouyang et al. 2014; Zhan et al. 2014; Hao et al. 2015; Petersen et al. 2015), including 18 provisionally designated powdery mildew resistance genes. However, many genes have lost resistance because of rapid mutation of the $B g t$ pathogen. Currently, only a few of these resistance genes, including Pm4, Pm16, Pm21, Pm24 and Pm30, have been used in production in China (Zeller and Hsam 1996; Szunics et al. 2001; Reader and Miller 1991; Cao et al. 2011).

Due to the complexity of genetic characteristics in common wheat, including allo-hexaploidy $(2 n=42)$, and its large genome $(17 \mathrm{~Gb})$ containing more than $80 \%$ repeat 
sequences, the major challenge is the high cost associated with the discovery, development and genotyping of a large number of SNPs (Belova et al. 2013). This challenge severely hampers the application of SNPs in wheat genetics research. Decreasing cost, along with rapid progress in next-generation sequencing (NGS) and the associated bioinformatics analyses have facilitated large-scale discovery of SNPs in crops. Genotyping by sequencing (GBS) methods, which combine reduced genome complexity using restriction enzymes with sequencing using NGS techniques, offer a greatly simplified library generation procedure that is more amenable for use with a large number of individuals or lines (Elshire et al. 2011). In common wheat, a genome-wide set of 1536 SNPs was used to evaluate linkage disequilibrium and population structure in a panel of 478 spring and winter wheat cultivars from 17 populations across the United States and Mexico (Chao et al. 2010). Nine thousand SNPs were also used in a worldwide sample of 2994 accessions of hexaploid wheat, including landraces and modern cultivars, to identify multiple targets of selection for crop improvement (Cavanagh et al. 2013).

The purpose of this study was to assess the prevalence of several known powdery mildew resistance gene locus in a collection of resistant germplasm from southwest China. In addition, genome-wide SNP markers were used to assess genetic variation in powdery mildew resistance in the germplasm collection and to identify new sources of powdery mildew resistance. Breeders will be able to use this information to design crosses generating new and potentially durable combinations of powdery mildew resistance in Chinese wheat.

\section{Materials and methods}

\section{Plant materials}

A set of 140 common wheat cultivars and breeding lines was selected to represent the germplasm used in the Sichuan and Guizhou Provinces during the last decade. The names and origins of the cultivars and breeding lines are presented in (Table $\mathrm{S} 1 *$ ).

In this study, cultivars were evaluated from three regions during two periods: Guiyang (Guizhou province), Hezhang (Guizhou province) and Mianyang (Sichuan province) during 2012-2013 and Guiyang (Guizhou province) during 2013-2014. The scores representing the highest disease severity of the powdery mildew reaction were used in the analysis. The host response (infection types) to powdery mildew was scored on a $0-4$ scale, in which $0,0,1,2,3$ and 4 represented immune, nearly immune, highly resistant, moderately resistant, moderately susceptible and highly susceptible, respectively (Mains and Dietz 1930).
*Further details about the Electronic Supplementary Material (ESM) can be found at the end of the article.

\section{DNA extraction and identification of Pm gene locus}

DNA was extracted from fresh leaf tissue from a single plant of each genotype using the protocol recommended by Triticarte Pty. Ltd. (http://www.triticarte.com.au). The primers used in this study are presented in (Table S2). SSR-PCR reactions were carried out according to Zhang et al. (2011).

\section{DArT-seq genotyping}

Genotyping was conducted by Diversity Arrays Technology Pty Ltd. (DArT P/L, Kirinari st., Bruce, Australia) using the DArT-seq method (Jaccoud et al. 2001). Marker positions on the contigs were identified using the best alignment of the marker or tag to an existing model genome. Call rates were measured for all SNP markers, and those markers with call rates $<80 \%$ were discarded. The allele frequencies of the remaining markers were then calculated, and those markers for which the frequency of the minor allele was $<2.5 \%$ were discarded.

\section{Statistical analyses}

Polymorphism information content (PIC) values were calculated for each SNP marker using the formula $\mathrm{PIC}=1-\sum(\mathrm{P} i)^{2}$, where $\mathrm{P} i$ is the proportion of the population carrying the $i$ th allele. Using the Statistical Package for Social Sciences software, version 13, Pearson correlation coefficients $(r)$ were calculated to determine the relationships between $P m$ genes carried by the cultivars and the type of powdery mildew infection, using Student's $t$ test with two levels of significance: $\alpha=0.05$ and $\alpha=0.01$. A binary matrix was produced from the SNP data by scoring fragments as 1 or 0 for the presence or absence of a specific marker allele, respectively. Consistent $0 / 1$ data matrices were used as input for genetic diversity. The DARwin analysis software, version 6.0.10, was used to calculate a genetic distance matrix. We also constructed a weighted neighbour-joining (NJ) method dendrogram. The reliability and goodness of fit of the dendrograms obtained from the SNP data were evaluated by bootstrapping based on 1000 samples (Felsenstein 1985). The DARwin analysis software was used to perform principal component analysis. 


\section{Results}

\section{Resistance of wheat varieties to Bgt at the adult plant stage}

On average, $52 \%$ of the varieties showed resistance in all four different growing conditions. The majority of the cultivars $(72.9 \%)$ exhibited resistance to the disease in Guiyang in 2014, while nearly half were resistant at the other three sites in 2013. Overall, 36 varieties $(25.71 \%)$ showed resistance at all four different growing conditions, including 31 registered varieties from Guizhou and 5 from Sichuan provinces (Table S3).

\section{Distribution of $P m$ gene locus}

To determine the distribution of powdery mildew resistance gene loci in wheat in southwest China, molecular makers closely associated with six Pm gene loci were scanned against a panel of 140 accessions. Fragments of all markers were clearly amplified and all showed polymorphisms (Table S4). Most cultivars (79.9\%) carried Pm30, while the Pml6 gene locus had the lowest frequency $(<20 \%)$ in our collection.

The frequencies of $P m$ gene loci carried by resistant and susceptible cultivars varied widely (Table S5). The frequencies of Pm4, Pm24 or Pm30 were not significantly different between resistant and susceptible cultivars. However, the frequencies of $P m 8, P m 16$ and $P m 21$ were significantly different among varieties with different disease reaction types. The resistant cultivars carried $P m 8$ and $P m 16$ at a lower frequency than did the susceptible cultivars. Pm4 and Pm21 were present at higher frequencies in the resistant than the susceptible cultivars. Especially for $P m 21$, the frequency differed by almost tenfold between the resistant and susceptible cultivars.

\section{Correlation between $\mathrm{Pm}$ gene locus and resistance to powdery mildew}

To reveal the effects of the $P m$ gene loci on resistance to powdery mildew in wheat cultivars in southwest China, correlations between each $\mathrm{Pm}$ gene locus and resistance in the corresponding cultivar among the four different environments were calculated (Table S6). Eleven significant correlations were observed. Among them, four resistance genes locus (Pm4,Pm8, Pm16 and Pm21) were significantly associated with disease resistance in one, two, three or four of the environments. Specifically, $P m 21$ was significantly positively associated with disease resistance at a level of 0.01 in all environments, with an $r$-value ranging from 0.53 to $0.81 . P m 16$ showed significant positive correlations with resistance to powdery mildew at three sites, with $r$-values ranging from 0.18 to 0.20 , while $P m 4$ was significantly associated with resistance at only a single site. $\operatorname{Pm} 8$ showed significant negative correlations at three sites, with $r$-values ranging from -0.31 to -0.39 . The correlation coefficients of the number of $P m$ genes pyramided in cultivars and their resistance in each environment were also calculated. The $r$-values associated with the significant positive correlations observed at the 0.01 level ranged from 0.21 to 0.31 .

\section{Genome-wide genotyping using SNP markers}

A total of 6486 SNPs were used to examine genetic diversity. The average heterozygosity, calculated from the SNP markers, was low (1.2\%), as expected for loci from autogamous plants. The average PIC value for the SNPs was 0.28 , and the median was 0.26 .

The Dice genetic distance was calculated using genotyping data from 6486 informative markers between all possible accession pairs, and it ranged from 0.01 to 0.33 , with a mean value of 0.25 . The consensus tree obtained showed that the accessions were clustered together primarily based on their origins, forming two distinct groups (Figure S1). The bootstrapped values $>70 \%$ are also indicated. The first group (G1), composed of two subgroups, contained 87 cultivars. The first subgroup was composed of 37 cultivars primarily from the Sichuan region. The second subgroup (SG2) included 50 cultivars from Sichuan, Guizhou and other regions of China. The second group (G2) contained 54 cultivars, primarily from Guizhou. Moreover, three clusters were identified in SG2, and these cultivars clustered primarily based on their origin or pedigree. For example, accessions from Sichuan and Guizhou were grouped together in the first cluster (from TX43 to YP1 and from JYP2 to CA9722). G2 represents two major clusters, one of which corresponds to accessions from Guizhou derived primarily from a cross between common wheat and its wild relatives. The majority (70.4\%) of Pm21-carrying cultivars were located in G2, while few were found in G1.

\section{Discussion}

\section{The discrepancy in resistance performance}

The unique mountainous terrain, cropping systems, landscape and favourable environmental conditions of southwest China (Cao et al. 2015a) allow powdery mildew pathogens to survive the summers in these areas (Lu et al. 2015; Liu et al. 2012). In our study, we found that adult-stage cultivars from different regions exhibited different levels of resistance to powdery mildew. Guizhou and Sichuan cultivars showed 
high resistance to $B g t$, and 36 varieties presented resistance in all four environments evaluated, 31 of which were from Guizhou and 5 from Sichuan. In addition, the frequencies of resistant varieties in the different environments were similar, except in the Guiyang site in 2014, which may be a result of dry weather that year. This suggested that the pathogenicity conferred by Bgt was similar between Guizhou and Sichuan. Southwest China, therefore, is particularly at risk, but also very suitable for breeding wheat resistant to powdery mildew.

\section{The distribution of $\mathrm{Pm}$ gene locus}

For utilization of resistant germplasm in southwest China, it is necessary to understand the distribution of $P m$ gene loci. In this study, the frequencies of $P m 21$ gene locus carriers in Guizhou, Sichuan and other regions were $60.0 \%$, $22.0 \%$ and $8.7 \%$, respectively. On average $38.1 \%, 12.9 \%$ and $56.8 \%$ of lines carried the $P m 8, P m 16$ and $P m 24$ gene locus, respectively. Similar results were reported in other studies. In an investigation of $P m 21$ distribution in Chinese winter wheat and breeding lines, Jiang et al. (2014) found that $34.4 \%$ of the lines carried this gene in the southwestern winter wheat region and 3.3\% in other regions of China. Among 145 wheat cultivars from 11 main production provinces in China, the frequency of the $P m 8$ gene was $52.4 \%$, while the frequencies of Pm16, Pm21 and Pm24 were lower than 10\% (Lei et al. 2015). Among 908 wheat cultivars from the Henan province, $63.9 \%$ carried the $P m 8$ gene, while fewer carried Pm4 or Pm21 (2/518 cultivars for each gene) (Cao et al. 2015b). Breeders in southwest China have a tendency to breed varieties resistant to the disease because of environmental pressures, while those in northern China prefer wheat cultivars producing high yields. This is one of the reasons the $P m 8$ gene, which was detected at a high frequency in wheat cultivars, no longer confers resistance to powdery mildew in China, especially in northern China.

\section{Correlation between Pm genes and powdery mildew resistance}

Some of the Pm genes, including Pm24 and Pm30, no longer confer resistance to powdery mildew in southwest China. Although Pm24 still confers resistance to current $B g t$ strains in some regions of China (Chen et al. 2013), there was no correlation between $P m 24$ and infection type at any of the four environments evaluated, suggesting that $P m 24$ is ineffective against powdery mildew in southwest China. Some studies have shown that the virulence frequency of $P m 30$ is higher in major wheat regions of China (Cao et al. 2010). In this study, $P m 8$ was not correlated with infection type at any of the four growing conditions, indicating that this gene no longer provides resistance to the Bgt pathogen in these regions. Moreover, $\mathrm{Pm} 4$, which has been used in breeding programs since the early 1990 s, still displays robust resistance to this disease in major wheat-growing regions of China (Lei et al. 2015). Our results are in agreement with other reports on Pm4. This gene was significantly associated with resistance at three of the four growing conditions in our study, demonstrating that the gene also has an effect in southwest China. More importantly, the Pm21 gene showed a significant association with disease infection type in all environments, with a mean $r$-value of -0.66 , suggesting that this gene currently plays an important role in wheat resistance to powdery mildew in southwest China. Other researchers have also shown that $P m 21$ exhibits a low virulence frequency and may display an immune response to pathogenic challenge in all populations in Sichuan province (Bie et al. 2015; Liu et al. 2015). Pm21 is present at high frequency in wheat cultivars of the Guizhou and Sichuan provinces, which may result in pathogen directional selection in these regions in the future.

\section{Genome-wide genotyping using SNP markers}

Genetic information is a prerequisite for improving resistance, maintaining yield stability and increasing yield in the wheat industry. Based on genotyping data using 8764 SNPs at the whole genome level, NJ cluster analysis showed that all cultivars evaluated fell into two groups (G1 and G2) based on their origin or pedigree. The majority of cultivars from Sichuan and other regions, as well as a few Guizhou cultivars, were clustered in G1. This clustering may be explained by the presence of certain important developmental genes, possibly involved in selection or adaptation to local environments (Zhang et al. 2011). G2 consisted primarily of Guizhou cultivars, indicating that these cultivars are heterogeneous compared with the cultivars in G1. Pairs of cultivars were closely related according to the pedigreebased analysis, but markedly less so according to the cluster analysis using molecular marker data. This is likely because we did not obtain accurate pedigree information for all cultivars, and some cultivars with high similarities in SNP loci were placed in a group.

Regions exhibiting differential selection could be associated with specific chromosomal loci representing candidate targets for intensive breeding (Crossa et al. 2007) and could also have an impact on the separation of population subgroups. For example, it was reported that markers on chromosome 2D near the Rht8 locus had a major impact on the population structure of European hexaploid bread wheat, and different $R h t 8$ alleles were found between Group I (GrI) and Group II (GrII) (Nielsen et al. 2014). Zhang et al. (2011) reported that two groups (1RS/1BL translocation and non-1RS/1BL translocation groups) were apparent in principal-coordinates analysis (PCoA) and DArTs analyses of 
population structure among 118 wheat cultivars from northern China. In this study, 140 cultivars formed two groups based primarily on the presence of the Pm21 locus. Except for a few cultivars, most $P m 21$ carriers were clustered in G2. Considering that $P m 21$ is derived from the T6VS/6AL lines, and that a low frequency of pairing and recombination occurs between chromosome 6VS from $\mathrm{H}$. villosa and 6AS from cultivated wheat species (Cao et al. 2011), it is very possible that cultivars in G2 are T6VS/6AL lines. While several cultivars were scattered in G1, these lines may carry 6VS segments of different sizes.

Host resistance is likely to be more permanent when several resistance genes are pyramided in a single wheat variety. Therefore, information about the distribution of $\mathrm{Pm}$ genes and genetic diversity in a collection of wheat varieties from southwest China will be important for pyramiding resistance genes. Because of unique climate characteristics, the Guizhou province is particularly suitable for resistance evaluation and wheat breeding. Based on the results of this study, breeding in these regions in the future could improve the generation of cultivars resistant to powdery mildew by means of marker-assisted selection.

Acknowledgements This work was supported by the National Natural Science Foundation of China (31160281, 31260321), the International Technology and Technology Cooperation Program of Guizhou province (G20137039) and the Project of Technological Activities for Students Studying Abroad in Guizhou Province (201301).

Open Access This article is licensed under a Creative Commons Attribution 4.0 International License, which permits use, sharing, adaptation, distribution and reproduction in any medium or format, as long as you give appropriate credit to the original author(s) and the source, provide a link to the Creative Commons licence, and indicate if changes were made. The images or other third party material in this article are included in the article's Creative Commons licence, unless indicated otherwise in a credit line to the material. If material is not included in the article's Creative Commons licence and your intended use is not permitted by statutory regulation or exceeds the permitted use, you will need to obtain permission directly from the copyright holder. To view a copy of this licence, visit http://creativecommons.org/licenses/by/4.0/.

\section{References}

Belova T, Zhan B, Wright J, Caccamo M, Asp T, Simková H, Kent M, Bendixen C, Panitz F, Lien S, Doležel J, Olsen OA, Sandve SR (2013) Integration of mate pair sequences to improve shotgun assemblies of flow-sorted chromosome arms of hexaploid wheat. BMC Genom 14:222

Bennett FGA (1984) Resistance to powdery mildew in wheat: a review of its use in agriculture and breeding programs. Plant Pathol 33:279-300

Bie T, Zhao R, Zhu S, Chen S, Cen B, Zhang B, Gao D, Jiang Z, Chen T, Wang L, Wu R, He H (2015) Development and characterization of marker MBH1 simultaneously tagging genes Pm21 and PmV conferring resistance to powdery mildew in wheat. Mol Breed $35: 189$
Cao X, Zhou Y, Duan X, Song Y, He W, Ding K, Wang B, Xia X (2010) Postulation of wheat powdery mildew resistance genes in 101 wheat cultivars (lines) from major wheat-cultivating regions in china. J Triticeae Crops 30:948-953 (in Chinese with English abstract)

Cao A, Xing L, Wang X, Yang X, Wang W, Sun Y, Qian C, Ni J, Chen Y, Liu D, Wang X, Chen P (2011) Serine/threonine kinase gene Stpk-V, a key member of powdery mildew resistance gene Pm21, confers powdery mildew resistance in wheat. P Natl Acad Sci USA 108:7727-7732

Cao S, Luo H, Jin M, Jin S, Duan X, Zhou Y, Chen W, Liu T, Jia Q, Zhang B, Huang J, Wang X, Shang X, Sun Z (2015a) Intercropping influenced the occurrence of stripe rust and powdery mildew in wheat. Crop Prot 70:40-46

Cao T, Chen Y, Li D, Zhang Y, Wang X, Zhao H, Liu Z (2015b) Identification and molecular detection of powdery mildew resistance of new bred wheat varieties (lines) in Henan Province, China. Acta Agron Sin 41:1172-1182 (in Chinese with English abstract)

Cavanagh CR, Chao S, Wang S, Huang BE, Stephen S, Kiani S, Forrest K, Saintenac C, Brown-Guedira GL, Akhunova A, See D, Bai G, Pumphrey M, Tomar L, Wong D, Kong S, Reynolds M, da Silva ML, Bockelman H, Talbert L, Anderson JA, Dreisigacker S, Baenziger S, Carter A, Korzun V, Morrell PL, Dubcovsky J, Morell MK, Sorrells ME, Hayden MJ, Akhunov E (2013) Genome-wide comparative diversity uncovers multiple targets of selection for improvement in hexaploid wheat landraces and cultivars. P Natl Acad Sci USA 110:8057-8062

Chao S, Dubcovsky J, Dvorak J, Luo MC, Baenziger SP, Matnyazov R, Clark DR, Talbert LE, Anderson JA, Dreisigacker S, Glover K, Chen J, Campbell K, Bruckner PL, Rudd JC, Haley S, Carver BF, Perry S, Sorrells ME, Akhunov ED (2010) Population and genome-specific patterns of linkage disequilibrium and SNP variation in spring and winter wheat (Triticum aestivum L.). BMC Genom 11:727

Chen X, Cao Y, Song J, Luan Z, Zhu G (2013) Analysis on the race population and virulence dynamics of blumeria graminis $\mathrm{f} . \mathrm{sp}$ tritici in some major wheat growing regions of china during 20112012. J Triticeae Crops 33:584-588 (in Chinese with English abstract)

Crossa J, Burgueno J, Dreisigacker S, Vargas M, Herrera-Foessel SA, Lillemo M, Singh RP, Trethowan R, Warburton M, Franco J, Reynolds M, Crouch JH, Ortiz R (2007) Association analysis of historical bread wheat germplasm using additive genetic covariance of relatives and population structure. Genetics 177:1889-1913

Elshire RJ, Glaubitz JC, Sun Q, Poland JA, Kawamoto K, Buckler ES, Mitchell SE (2011) A robust, simple genotyping-by-sequencing (GBS) approach for high diversity species. PLoS ONE 6:e19379

Felsenstein J (1985) Confidence limits on phylogenies: an approach using the bootstrap. Evolution 39:783-791

Hao Y, Parks R, Cowger C, Chen Z, Wang Y, Bland D, Murphy JP, Guedira M, Brown-Guedira G, Johnson J (2015) Molecular characterization of a new powdery mildew resistance gene Pm54 in soft red winter wheat. Theor Appl Genet 128:465-476

Hulbert SH, Webb CA, Smith SM, Sun Q (2001) Resistance gene complexes: evolution and utilization. Annu Rev Phytopathol 39:285-312

Jaccoud D, Peng K, FeinStein D, Kilian A (2001) Diversity arrays: a solid state technology for sequence information independent genotyping. Nucleic Acids Res 29:e25

Jiang Z, Wang Q, Wu J, Xue W, Zeng Q, Huang L, Kang Z, Han D (2014) Distribution of powdery mildew resistance gene $P m 21$ in Chinese winter wheat cultivars and breeding lines based on genespecific marker. Scientia Agric Sin 47:2078-2087 (in Chinese with English abstract) 
Lei X, Du J, Sun G (2015) Identification of powdery mildew resistance of wheat cultivars (lines) and practicability of related molecular markers. J Triticeae Crops 35:37-44 (in Chinese with English abstract)

Liu N, Gong G, Zhang M, Zhou Y, Chen Z, Yang J, Chen H, Wang X, Lei Y, Liu K (2012) Over-summering of wheat powdery mildew in Sichuan Province. China Crop Prot 34:112-118

Liu N, Liu ZL, Gong G, Zhang M, Wang X, Zhou Y, Qi X, Chen H, Yang J, Luo P, Yang C (2015) Virulence structure of blumeria graminis f. sp. tritici and its genetic diversity by issr and srap profiling analyses. PLoS ONE 10:e0130881

Lu Y, Wu X, Yao M, Zhang J, Liu W, Yang X, Li X, Du J, Gao A, Li L (2015) Genetic mapping of a putative agropyron cristatumderived powdery mildew resistance gene by a combination of bulked segregant analysis and single nucleotide polymorphism array. Mol Breed 35:96

Mains EB, Dietz SM (1930) Physiologic forms of barley mildew, Erysiphe graminis hordei Marchal. Phytopathology 20:229-239

McIntosh RA, Dubcovsky J, Rogers WJ (2014) Catalogue of gene symbols for wheat: 2013-2014 supplement in: KOMUGI-integrated wheat science database at http://www.shigen.nig.ac.jp/wheat/ komugi/genes/symbolClassList.jsp

Nielsen NH, Backes G, Stougaard J, Andersen SU, Jahoor A (2014) Genetic diversity and population structure analysis of European hexaploid bread wheat (Triticum aestivum 1.) varieties. PLoS ONE 9:e94000

Ouyang S, Zhang D, Han J, Zhao X, Cui Y, Song W, Huo N, Liang Y, Xie J, Wang Z, Wu Q, Chen YX, Lu P, Zhang DY, Wang L, Sun H, Yang T, Keeble-Gagnere G, Appels R, Doležel J, Ling HQ, Luo M, Gu Y, Sun Q, Liu Z (2014) Fine physical and genetic mapping of powdery mildew resistance gene mliw172 originating from wild emmer (Triticum dicoccoides). PLoS ONE 9:e100160

Petersen S, Lyerly JH, Worthington ML, Parks WR, Cowger C, Marshall DS, Brown-Guedira G, Murphy JP (2015) Mapping of powdery mildew resistance gene Pm53 introgressed from aegilops speltoides into soft red winter wheat. Theor Appl Genet 128:303-312

Reader SM, Miller TE (1991) The introduction into bread wheat of a major gene for resistance to powdery mildew from wild emmer wheat. Euphytica 53:57-60

Szunics L, Szunics L, Vida G, Bedo Z, Svec M (2001) Dynamics of changes in the races and virulence of wheat powdery mildew in Hungary between 1971 and 1999. Euphytica 119:145-149

Xiao M, Song F, Jiao J, Wang X, Xu H, Li H (2013) Identification of the gene Pm47 on chromosome 7BS conferring resistance to powdery mildew in the chinese wheat landrace hongyanglazi. Theor Appl Genet 126:1397-1403

Zeller FJ, Hsam SLK (1996) Chromosomal location of a gene suppressing powdery mildew resistance genes $P m 8$ and $P m 17$ in common wheat (Triticum aestivum L.). Theor Appl Genet 93:38-40

Zhan H, Li G, Zhang X, Li X, Guo H, Gong W, Jia J, Qiao L, Ren Y, Yang Z, Chang Z (2014) Chromosomal location and comparative genomics analysis of powdery mildew resistance gene $P m 51$ in a putative wheat-thinopyrum ponticum introgression line. PLoS ONE 9:e113455

Zhang LY, Liu DC, Guo XL, Yang WL, Sun JZ, Wang DW, Sourdille P, Zhang AM (2011) Investigation of genetic diversity and population structure of common wheat cultivars in northern china using dart markers. BMC Genet 12:42 